\title{
STRENGTHENING OF THE NET SECTION OF STEEL ELEMENTS UNDER TENSILE LOADS WITH BONDED CFRP STRIPS
}

\author{
Penagos-Sanchéz D.M. ${ }^{1}$, Légeron F. ${ }^{2}$, Demers M. ${ }^{3}$ and Langlois, S. ${ }^{4}$
}

\begin{abstract}
The use of CFRP is increasingly common as a solution for the strengthening of structures, but the majority of research and applications have focused on the retrofit of concrete structures. The application of CFRP adhesively bonded to enhance the load carrying capacity of metallic elements has been widely studied in the aeronautical industry but is also a promising technique for the civil engineering area. This paper presents an experimental study to verify the effectiveness of the use of CFRP for the strengthening of the net section of steel elements under tensile loading. A series of tensile tests were conducted with different bond lengths, different number of layers and different surface preparation of steel elements in double lap joints and steel plates. The ultimate load, the failure mode and the effective bond length for CFRP strengthened specimens were determined. The results showed that using CFRP sheets for the strengthening against net area failure provides no gain on the ultimate state, provides a small gain at the elastic limit, and provides a larger gain if the designer accepts to increase the capacity from the elastic limit to the debondig limit.
\end{abstract}

Keywords: bonded CFRP strips, surface preparation, lap joint, net section, reinforcement of steel elements.

\section{INTRODUCTION}

The standard techniques of rehabilitation of steel structures that include bolting or welding of steel plates to the existing system has some drawbacks such as the durability, the use of lifting and

\footnotetext{
${ }^{1}$ Master degree candidate, Dept. of Civil Engineering, Univ. of Sherbrooke, Sherbrooke, QC, J1K 2R1, Canada.

${ }^{2}$ Professor, Dept. of Civil Engineering, Univ. of Sherbrooke, Sherbrooke, QC, J1K 2R1, Canada.

${ }^{3}$ Research Associate, Dept. of Civil Engineering, Univ. of Sherbrooke, Sherbrooke, QC, J1K 2R1, Canada.

${ }^{4}$ Postdoctoral fellow, Dept. of Civil Engineering, Univ. of Sherbrooke, Sherbrooke, QC, J1K 2R1, Canada.
} 
drilling/welding equipment, the placement of falsework and the addition of permanent load to the structure and the difficulty of fitting complex profiles.

For this reason, there is a growing need for the development and implementation of new methods for fast and efficient rehabilitation of deteriorated structural steel components.

Fiber reinforced polymer (FRP) materials combine high-strength, high-modulus fibers with a polymeric matrix that ensures load transfer between the fibers. FRP materials are recommended for structural rehabilitation solutions, as these materials are lightweight, corrosion resistant and can fit complex geometry.

In the construction sector, the use of FRP is increasingly common as a solution for the strengthening or retrofitting of structures, but the majority of the research and applications of FRP has focused on the retrofit of concrete structures. There is comparatively little work investigating the use of bonded FRP for the strengthening of steel members. Most of the available research and guidance to strengthen steel structures focuses on the use of FRP to improve the behavior of components subject to bending, applying these materials to the tensile flange of a section to increase its capacity (Mertz and Gillespie 1996; Schnerch et al. 2007; Rizkalla et al. 2008); to enhance fatigue performance (Bassetti et al. 1999; Bocciarelli et al. 2009; Jones and Civjan 2003; Tavakkolizadeh and Saadatmanesh 2003a), to improve local or member stability (Harries et al. 2008; Harries et al. 2009; Shaat and Fam 2006) and to repair fractures of steel members (Colombi et al. 2003; Photiou et al. 2006; Tavakkolizadeh and Saadatmanesh 2003b). Limited research has been conducted to improve the behavior of steel members under tensile loading (Bocciarelli et al. 2007; Colombi and Poggi 2006; Lam et al. 2007).

The challenges to the use of FRP reinforcement in steel structures are: the FRP adhesion to steel, because the weakest link in the bonding of carbon fiber reinforced polymer (CFRP) elements to metallic joints is the adhesive bond (Al-Emrani et al. 2005; Buyukozturk et al. 2004; Fernando 2010; Qaidar and Karunasena 2010; Zhao and Zhang 2007); the surface preparation because the integrity of the joint is dependent on preparation procedures (Cadei et al. 2004; Harris and Beevers 1999; Packham 2003; Schnerch et al. 2004); and the prevention of galvanic corrosion resulting 
from the contact of carbon fibers and steel (Tavakkolizadeh and Saadatmanesh 2001). In particular, the bonding of CFRP on steel is critical because steel may undergo very large deformations before reaching complete failure. In the case of net area failure at connections, the yielding zone is very localized and it may be possible to strengthen the connection with CFRP layers.

The objective of this paper is to identify configurations that allow the strengthening of bolted steel section against net-section rupture. The experimental results of a series of double lap shear specimens tested in tension to investigate the effect of surface preparation on the bond strength between CFRP and steel plates are presented and compared to analytical predictions. Discussions are made on failure modes, ultimate load carrying capacity and effective bond length for these specimens. Then, the experimental results of a series of steel plate specimens reinforced by CFRP strips and tested under tensile loading to investigate the effect of net area/gross area $\left(A_{n} / A_{g}\right)$ ratio are presented and compared with a theoretical model. Finally, the effect of the numbers of layers and their configuration is studied with a second series of steel plate specimens.

\section{EXPERIMENTAL PROGRAM}

The experimental program consists of three phases:

1. Effect of anchor length and surface preparation.

2. Evaluation of the composite material contribution with changing net / gross area ratio.

3. Effect of the number of layers of CFRP composite sheet materials on steel plates.

Phase I was conducted to determine the optimal steel surface preparation and to select the CFRP material and the minimal lap length. Phases II and III were conducted to study the influence of the amount and configuration of CFRP according to the joint characteristics.

The tests were carried out on two basic types of specimen:

- Double lap joints for Phase I

- Steel plate with single and double side reinforcement for Phases II and III

All the specimens were subjected to axial tensile load. 


\section{Material Properties}

Tension coupons of steel plates were prepared and tested according to ASTM A370-02. The average elastic modulus $\left(E_{s}\right)$, yield strength $\left(f_{y}\right)$ and ultimate strength $\left(\sigma_{u l t}\right)$ are shown in Table 1. All the steel plates are from the same batch, therefore the values for $f_{y}$ and $\sigma_{u l t}$ are the same for all the specimens.

Two different types of CFRP material were used in the experimental program: sheets and plates. The sheets used were bidirectional carbon fabric (Foreva TFC) with a width of $90 \mathrm{~mm}$ and the thickness of the ensemble (fiber and epoxy) is $0.48 \mathrm{~mm}$. The properties provided by the manufacturer are reported in Table 1. A bi-component epoxy resin Foreva Epx TFC was used for bonding the fabric to the specimens. The mixing ratio of the epoxy by weight was two parts of component A (resin) to one part of component B (hardener). The epoxy had a pot life of $1 \mathrm{~h} 30 \mathrm{~min}$ at $20^{\circ} \mathrm{C}$.

The CFRP plates used were pultruded carbon fiber laminates (Sika Carbodur S1525) with a width of $15 \mathrm{~mm}$ and a thickness of $2.5 \mathrm{~mm}$. The properties provided by the manufacturer are reported in Table 1. A two component epoxy resin Sikadur 330 was used to bond the carbon plates to the specimens. The mixing ratio in this case was four part of component A (resin) to one part of component B (hardener) by weight. The epoxy had a pot life of $30 \mathrm{~min}$ and was cured at room temperature.

\section{Specimen Preparation and Test Setup}

The steel plates surfaces were treated using three different techniques: by abrasive disk or sandpaper in the case of common steel and by steel brush for galvanized steel. A white steel surface to expose bare metal was reached with the abrasive disk. The sandpaper surface preparation left most of the black scale but removed any debris and protuberances. Only the steel brush was used on the galvanized steel to avoid damaging the zinc coat while removing dirt and debris. Before bonding, the steel plates and CFRP laminates were cleaned with methyl ethyl ketone to remove dust and grease. The two component epoxy resin was prepared according to the instruction manual provided by the manufacturer. To form the bond, the resin was applied to the steel surfaces with a 
roller in the case of CFRP sheets and with a spatula in the case of CFRP laminates. The surfaces were then squeezed together with a small pressure to force out air voids and excess epoxy adhesive. Subsequently, specimens were allowed to cure at room temperature for a minimum of 7 days before testing. A special attention was taken to keep a uniform thickness of the adhesive. However, this thickness was not measured and controlled in order to reproduce field conditions.

\section{Effect of anchor length and surface preparation}

The specimens consist in double lap joints that were made using two CFRP strips bonded to two steel plates separated by a gap of $2 \mathrm{~mm}$ (Fig. 1). The aim of the experiment was to investigate the optimal anchor length of CFRP material in accordance to steel surface preparation. The study of the effect of anchor length was performed for anchor lengths ranging from $100 \mathrm{~mm}$ to $200 \mathrm{~mm}$ with two CFRP materials types: sheet and plate. For both CFRP types, three surface preparations were evaluated, namely: white metal with abrasive disk, sandpaper cleaning of black steel and steel brush cleaning of galvanized steel. Two repetitions were made for each condition for a total of 36 specimens. The details dimensions of the specimens are shown in Table 2 and the geometry is illustrated in Fig. 1.

\section{Evaluation of the composite material contribution according to the net / gross area ratio}

The specimens were made of $6.35 \mathrm{~mm}\left(1 / 4^{\prime \prime}\right)$ thick by $100 \mathrm{~mm}$ wide steel plates characterized by three different configurations of one or two circular holes of $17.5 \mathrm{~mm}$ (11/16") or 23.8 $\mathrm{mm}(15 / 16 ")$ diameter and reinforced with one layer of CFRP sheets. The anchor length of the CFRP layer measured from the end of the hole was of $150 \mathrm{~mm}$ or $225 \mathrm{~mm}$, and the steel surface preparation was with steel brush for all the specimens. In each specimen's hole a bolt and washer were installed to reproduce the condition and the real difficulties during the placement of the CFRP sheets. The CFRP was applied after the bolt and washer were inserted into the hole and the fiber was split to go around the bolt. Bolt diameter was $15.9 \mathrm{~mm}\left(5 / 8^{\prime \prime}\right)$ and $22.2 \mathrm{~mm}$ (7/8") for the 17.5 $\mathrm{mm}$ and $23.8 \mathrm{~mm}$ holes respectively. Steel specimens without CFRP sheets were tested to provide a reference. The aim of the experiment was to investigate the contribution of CFRP material in accordance to the variability of the net/gross cross sectional area of steel ratio, $A_{n} / A_{g}$. Two rep- 
etitions were made of each test configuration for a total of 36 specimens. The dimensions of the specimens and the three hole configurations are illustrated in Fig.2.

\section{Effect of the number of layers of CFRP}

The specimens were made of $6.35 \mathrm{~mm}$ thick by $100 \mathrm{~mm}$ wide steel plates characterized by one circular hole of $23.8 \mathrm{~mm}(15 / 16 ")$ diameter (i.e. $A_{n} / A_{g}=76 \%$ ) and single or double side reinforcement using different number of CFRP sheets layers (one to six layers) as shown the figure 3. The anchor length of the CFRP layers was measured from the end of the hole and surface preparation was made with steel brush or abrasive disk. In each specimen's hole was installed a $22.2 \mathrm{~mm}$ (7/8") diameter bolt to reproduce the conditions and real difficulties during the placement of the CFRP sheets. The CFRP was applied after the bolt and washer were inserted into the hole and the fiber was split to go around the bolt.

The main objective of this part of the experiment was to investigate the contribution of the number of layers of CFRP material for a given $A_{n} / A_{g}$. On the other hand, it was attempted to study other variables such as: the effect of tapering and anchor length between layers of CFRP; the effect of reinforcing one side or both sides of the steel plate and; the effect of partial surface preparation. The partial surface preparation consisted in to expose bare metal with the abrasive disk only in the $L_{L}$ section which is anchored the CFRP. The dimensions of the specimens are shown in the figure 3 and Table 6 . A total of 26 specimens were prepared with 18 different configurations because eight configurations have two specimens.

The axial tensile static tests for all phases were performed in a universal testing machine with a nominal capacity of $500 \mathrm{kN}$. The double lap specimens of Phase I were tested under displacement control at a constant rate of $0.5 \mathrm{~mm} / \mathrm{min}$. Continuous steel plates specimens for Phases II and III were tested at $0.5 \mathrm{~mm} / \mathrm{min}$ up to $2.5 \mathrm{~mm}$ and then the rate was increased to $3 \mathrm{~mm} / \mathrm{min}$ up to failure.

\section{TEST RESULTS}




\section{Effect of anchor length and surface preparation}

\section{Failure mode}

The failure of bonded CFRP-steel joints could occur in the base material, in the adhesive layer or at an interface between two materials (Zhao and Zhang 2007). The rupture of all specimens in this part of the study occurred at or near the adhesive-steel interface. On the sanded black steel specimen almost all epoxy adhesive was removed from the steel surface and part of the scale layer formed during the rolling of the steel was also removed (Fig. 4(a)). On the ground white steel surface a significant part of the epoxy adhesive was ripped off the steel (Fig. 4(b)). As shown in Fig. 4(c) the epoxy adhesive was completely detached from the galvanized steel surface but the zinc coat was not ripped off.

\section{Prediction of ultimate load and effective bond length}

Various theoretical analyses of adhesively bonded joints have been derived. (Hart-Smith 1973) extended the elastic analysis for double lap joints of (Volkersen 1938) by considering the nonlinear behavior of the adhesive. He proposed that the joint reaches its maximum strength when the maximum shear strain of the adhesive reaches its failure shear strain value. Detailed derivations can be found in (Hart-Smith 1973; Hart-Smith 1974).

Hart-Smith proposed expressions to predict the ultimate load carrying capacity per unit width for the inner and outer adherent of an adhesively bonded double-lap joint, taken as the lesser of:

$$
\begin{gathered}
P_{i}=\sqrt{2 \tau_{p} t_{a}\left(\frac{1}{2} \gamma_{e}+\gamma_{p}\right) 2 E_{i} t_{i}\left(1+\frac{E_{i} t_{i}}{2 E_{o} t_{o}}\right)} \\
P_{o}=\sqrt{2 \tau_{p} t_{a}\left(\frac{1}{2} \gamma_{e}+\gamma_{p}\right) 4 E_{o} t_{o}\left(1+\frac{2 E_{o} t_{o}}{E_{i} t_{i}}\right)}
\end{gathered}
$$

where $E_{i}$ and $E_{o}$ are the Young's modulus of the inner and outer adherent layers, $t_{i}$ and $t_{o}$ are the thickness of inner and outer adherent layers, $\tau_{p}$ is the adhesive shear strength, $\gamma_{e}$ and $\gamma_{p}$ are the elastic and plastic adhesive shear strains respectively, and $t_{a}$ is the adhesive thickness. For the configuration studied, the inner adherent is the steel plate and the outer adherend is the CFRP. 
Therefore, the ultimate load carrying capacity $P_{\text {ult }}$ predicted by Hart-Smith model becomes:

$$
P_{u l t}=b_{c} \min \left[P_{i}, P_{o}\right]
$$

Hart-Smith also proposed the following equation to predict the effective bond length, $L_{e}$, of a double lap joint:

$$
L_{e}=\frac{\sigma_{u l t} t_{i}}{2 \tau_{p}}+\frac{2}{\lambda}
$$

where $\sigma_{u l t}$ is the ultimate strength of the steel plate and

$$
\lambda=\sqrt{\frac{G_{a}}{t_{a}}\left(\frac{1}{E_{o} t_{o}}+\frac{2}{E_{i} t_{i}}\right)}
$$

in which $G_{a}$ is the adhesive shear modulus.

The load carrying capacity $P_{C F R P}$ for any bonded length, $L_{L}$, can be evaluated with Eq. 6 and Eq. 7 (Liu et al. 2005), assuming that the load is linearly proportional to the bond length:

$$
P_{C F R P}=L_{L} \frac{P_{u l t}}{L_{e}} \quad \text { if } L_{L} \leq L_{e}
$$

$$
P_{C F R P}=P_{u l t} \quad \text { if } L_{L}>L_{e}
$$

The Hart-Smith model was used to predict the strength of the double lap specimens with the following assumptions: the adhesive shear strength is estimated at about $80 \%$ of the ultimate strength of adhesive, the value of $\gamma_{p}$ is taken as 3 times $\gamma_{e}$ (Liu et al. 2005), the Poisson's ratio for the adhesive is assumed equal to 0.37 (Mays and Hutchinson 1992), the $t_{a}$ is taken as $0.25 \mathrm{~mm}$ and $1.50 \mathrm{~mm}$ for the specimens fabricated with CFRP sheets and CFRP plates respectively.

The ultimate loads obtained for the double lap joints in the tests are summarized in Table 3. The $L_{L}$ has been plotted against the ultimate loads and compared with the Hart-Smith model in Figs. 5 and 6 for CFRP sheets and CFRP plates respectively. 
It can be seen from these two figures that the ultimate load obtained using Eq. 3 is $64 \mathrm{kN}$ for the CFRP sheets-steel double lap joints and $48 \mathrm{kN}$ for the CFRP plates-steel double lap joints, which has good agreement with the average ultimate load for specimens for which the surface preparation was made with an abrasive disk. From the Hart-Smith model the values of $L_{e}$ are $85 \mathrm{~mm}$ and $97 \mathrm{~mm}$ for the CFRP sheets-steel double lap joints and CFRP plates-steel double lap joints; respectively.

For the CFRP sheets (Fig.5), the ultimate average load increased from $38.9 \mathrm{kN}$ to $65.3 \mathrm{kN}$ when the surface preparation is improved from steel brush to abrasive disk. The same occurs for the CFRP plates specimens (Fig.6), where the ultimate average load increased from $24.7 \mathrm{kN}$ to $48.5 \mathrm{kN}$ when the surface preparation is changed. Therefore, an $L_{L}$ of $100 \mathrm{~mm}$ is needed to reach the plateau capacity, which is in agreement with the theoretical prediction.

Outcomes of Eq.3 are also compared with the proposed expressions by (Bocciarelli and Colombi 2012) which predict the load carrying capacity of a CFRP reinforced tensile steel element in the elasto-plastic regime, taken as the lesser of:

$$
P_{f}^{e l-p l}= \begin{cases}\alpha P_{y}+2 A_{s} \sqrt{\frac{H_{s}}{t_{s}}(1+\delta) \gamma\left(G_{f}-\alpha G_{p}\right)} & \geq P_{y} \\ \frac{2 A_{s}}{\delta} \sqrt{\frac{E_{s}}{t_{s}}(\delta+1) G_{f}} & \leq P_{y} \\ 2 A_{s} \sqrt{\frac{E_{s}}{t_{s}}(\delta+1) G_{f}} & \leq P_{y}\end{cases}
$$

where

$$
\delta=\frac{E_{s} A_{s}}{2 E_{f} A_{f}} ; \quad \alpha=\frac{\left(E_{s}-H_{s}\right)(1+\delta)}{E_{s}(1+\delta)-H_{s} \delta}
$$

$$
\gamma=\frac{E_{s}}{E_{s}(1+\delta)-H_{s} \delta} \frac{b_{f}}{b_{s}} ; \quad G_{p}=\frac{1}{4 b_{f}} \frac{P_{y}^{2}}{E_{s} A_{s}(1+\delta)}
$$

The fracture energy was assumed equal to $G_{f}=0.815 \mathrm{~N} / \mathrm{mm}$ (Bocciarelli and Colombi 2012) for both CFRP materials and the steel hardening modulus was $788 \mathrm{MPa}$. It can be seen from Figs. 5 and 6 that the ultimate load obtained using Eq. 8 is $83 \mathrm{kN}$ for the CFRP sheets-steel double lap joints and $40 \mathrm{kN}$ for the CFRP plates-steel double lap joints. There is a better agreement with the 
average ultimate load for CFRP plates-steel double lap joints specimens tested which the surface preparation was made with an abrasive disk. However, a fracture energy value of $0.5 \mathrm{~N} / \mathrm{mm}$ is suggested for the CFRP sheets-steel double lap joints due to the difference of the CFRP. As a result, an ultimate load of $65 \mathrm{kN}$ will be obtained which is in better agreement with the average load of tested specimens.

The surface preparation has an important effect on the ultimate load of the joint. It is important to note that surface preparation with an abrasive disk takes more effort and time, and it can be complicated to do in field applications. For the next phase, the CFRP sheets were used, because they showed greater capacity and ease of installation around bolts.

\section{Evaluation of the composite material contribution according to the net / gross area ratio}

Some axial load versus displacement curves of the specimens with and without CFRP sheet reinforcement are shown in Fig. 7,8 and 9. The results are summarized in Table 4. For all specimens, debonding occurred at adhesive-steel interface.

It can be seen from Fig. 7, 8 and 9 that the initial loading was shared by the steel plate and the CFRP sheet. Then, after steel yielding of the minimum cross section, the additional load was mainly supported by the CFRP. As the load increased, the capacity of the specimen reached its peak when full CFRP sheet debonding occurred. At debonding, the load sharply decreased and from that point, the load is supported only by the steel up to the failure. In summary, specimens showed steel yielding first; which is the ideal failure mode. This is followed by the fiber debonding, and finally net section rupture occurred.

Table 5 shows that experimental values for the elastic $F_{e l}^{r e f}$ and ultimate $F_{u}^{r e f}$ limits of reference specimens (specimens without composite) correspond to those predicted with the theory, $f_{y} A_{n}$ and $\sigma_{u l t} A_{n}$. Therefore, for the analysis only the experimental values $F_{e l}^{r e f}$ and $F_{u}^{r e f}$ will be used to compare the capacity of steel plates when adding CFRP sheets. Whereas some design codes allow the yielding of the net area around a connexion, limiting the capacity to $\sigma_{u l t} A_{n}$ (S16-09), other design codes, (for example ASCE 10-97 for the design of transmission line towers), limit the capacity to $f_{y} A_{n}$. Due to the debonding that occurs when the gross section starts to yield, the 
ultimate capacity of the specimens with CFRP does not increase compared to $F_{u}^{r e f}$ of the steel plate alone. However, the CFRP sheets permit an increase in the elastic limit $F_{e l}$ as seen in the close ups of Fig. 7 to 9. The difference between $F_{e l}$ and $F_{e l}^{r e f}$ is shown in Fig. 10 for one layer of CFRP. It can be seen in this figure that the increase is small an that it shows a large scatter for high $A_{n} / A_{g}$ ratios.

It is also interesting to calculate the difference between the debonding force and $F_{e l}^{r e f}$. At the point just before debonding is reached, the response of the connection is mainly elastic. The designer may want to accept these small inelastic deformations and base the capacity of the assembly on $F_{\text {debonding }}$ rather than $F_{e l}$. Fig. 11 shows that the differnce between $F_{\text {debonding }}$ and $F_{e l}^{r e f}$ is important and can reach $56 \%$ of $F_{e l}^{r e f}$. It can be also seen from this figure, that the contribution of CFRP is greater when $A_{n} / A_{g}$ decreases (approximately $68 \mathrm{kN}$ for $A_{n} / A_{g}$ of $52 \%$ and $37 \mathrm{kN}$ for $A_{n} / A_{g}$ of $\left.83 \%\right)$. This is explained by the fact that for smaller $A_{n} / A_{g}$ ratios, net failure occurs well before the gross section failure of the plate. Also, it can be noticed that there is not a significant difference if the anchor length of CFRP is $150 \mathrm{~mm}$ or $225 \mathrm{~mm}$, because once the effective anchor length of the CFRP sheet is reached; no significant increase in axial load capacity will occur.

\section{Effect of the number of layers of CFRP}

The results are summarized in Table 6. As for the previous parts of the study, all specimens experienced debonding at the adhesive-steel interface.

The number of CFRP layers have been plotted against the difference between the debonding and elastic force of reinforced steel plates in Fig. 12. It can be seen from this figure, as previously observed, that specimens with surface preparation with an abrasive disk have higher strengths than specimens prepared with a steel brush. For the tested $N p$, the difference between the debonding and elastic force of reinforced steel plates decreases when the number of layers increases for both surface preparations. This is because the interfacial stress between the steel and the CFRP increases when the CFRP stiffness increases.

As mentioned in the previous section, the addition of CFRP changes the linear behavior of the steel plate. Fig. 13 presents the results of the difference between the elastic force of steel 
plates with and without reinforcement versus the number of CFRP layers. It can be noticed from Fig. 13 that the elastic force increases $(5 \mathrm{kN}$ approximately for each additional CFRP layer for single side reinforcement) when adding CFRP layers for this steel plate configuration $\left(A_{n} / A_{g}=\right.$ $76 \%$ ). This means that the elastic limit of a steel connection may be increased significantly if using several layers of CFRP. However, this is true only for the surface preparation with the abrasive disk. Indeed, it can be observed that the contribution of CFRP to the elastic force for specimens with the steel brush surface preparation reaches a plateau at $n=2$ because the adherence of the composite is limited by the scale layer of the steel plate, which is ripped off at failure.

Results show that, for the double side reinforced specimens, the elastic force increases between $10 \mathrm{kN}$ to $20 \mathrm{kN}$ for specimens with two and four layers of CFRP due to surface preparation (Fig. 13) compared with unreinforced specimens.

Using CFRP sheets of different length is introduced in some specimens to create a tapered effect to provide a gradual reduction of the CFRP stiffness in order to reduce the stress concentration at the extremities of the CFRP reinforcement. For specimens with four CFRP layers whose surface preparation was made with the abrasive disk (C3-S-4-taper-S2 tapered specimen and C3-S-4-210$\mathrm{S} 2$ equal length specimens) it can be noticed that the value of elastic force is similar, but that there was an increase of about $6 \%$ for the maximal debonding load due to tapering of layers.

Results for specimens with two CFRP layers show that the elastic and debonding force increases between $3 \%$ and $4 \%$ if the lap length of the second layer is longer, no matter the surface preparation.

Regarding the results of debonding and elastic force for specimens whose surface preparation was made partially or complete, it can be concluded that these two types of surfaces preparation are equivalent, because the difference between those loads are approximately $2 \%$. This indicates that surface preparation does not need to be perfect near bolts without compromising the performances of the CFRP reinforcement.

In summary, these experimental results showed that, adding CFRP layers decreased significantly the debonding load but increased significantly the elastic load. A designer may want to 
limit the number of layers if he or she is considering $F_{\text {debonding }}$ as the capacity limit, or contrarily use a larger number of layers if considering $F_{e l}$ as the capacity limit. The results also showed a small increase in debonding load when tapering layers and a very small influence of partial versus complete surface preparation with abrasive disk.

\section{CONCLUSIONS}

In this paper, an experimental study to verify the effectiveness of the use of CFRP strips for the strengthening of steel members under tensile loading was presented. The test parameters included: types of CFRP composite material (sheets and plates), lap length, steel surface preparation, number and configurations of CFRP layers.

Based on the experimental results, the following conclusions were made:

1. The axial load capacity of the bonded CFRP - steel joint is significantly affected by surface preparation.

2. As predicted by Hart-Smith, an anchor length of $100 \mathrm{~mm}$ is sufficient to develop the full capacity of CFRP sheets.

3. The Hart-Smith model predicts well the debonding force for specimens with the abrasive disk surface preparation.

4. A similar behavior was observed for specimens reinforced with CFRP sheets and CFRP plates. The CFRP sheets provided larger capacity and were easier to install around bolts.

5. All specimens failed by debonding at the adhesive-steel interface.

6. The contribution of CFRP is greater when $A_{n} / A_{g}$ decreased.

7. For the number of layers tested, the debonding load decreases with the increases of number of layers regardless of the surface preparation, but yielding load increases with the number of layers, in particular for the abrasive disk surface preparation.

8. The contribution of CFRP reinforcement to the elastic limit of the specimens is small for one layer, but becomes significant for multilayered configurations.

9. If considering that the capacity limit of the steel connection can be extended to the debond- 
ing force, the gain due to CFRP may reach up to $56 \%$ for $A_{n} / A_{g}$ of $52 \%$.

\section{ACKNOWLEDGMENTS}

This study was carried out as part of the research projects of Hydro-Québec (HQ) and Réseau de Transport d'Électricité (RTE) Industrial Research Chair on Overhead Transmission Line Structures at the Université de Sherbrooke, Québec. The financial support provided by HQ-RTE is gratefully acknowledged. Thanks are also expressed to Sika and Freyssinet for supplying the CFRP reinforcing materials. 


\section{REFERENCES}

Al-Emrani, M., Linghoff, D., and Kliger, R. (2005). "Bonding strength and fracture mechanisms in composite steel-CFRP elements." International Symposium on Bond Behaviour of FRP in Structures (BBFS 2005), International Institute for FRP in Construction.

Bassetti, A., Liechti, P., and Nussbaumer, A. (1999). "Fatigue resistance and repairs of riveted bridge members." European Structural Integrity Society, 23, 207-218.

Bocciarelli, M. and Colombi, P. (2012). "Elasto-plastic debonding strength of tensile steel/CFRP joints.” Engineering Fracture Mechanics, 85, 59-72.

Bocciarelli, M., Colombi, P., Fava, G., and Poggi, C. (2007). "Interaction of interface delamination and plasticity in tensile steel members reinforced by CFRP plates." International Journal of Fracture, 146(1-2), 79-92.

Bocciarelli, M., Colombi, P., Fava, G., and Poggi, C. (2009). "Fatigue performance of tensile steel members strengthened with CFRP plates.” Composite Structures, 87(4), 334-343.

Buyukozturk, O., Gunes, O., and Karaca, E. (2004). "Progress on understanding debonding problems in reinforced concrete and steel members strengthened using FRP composites." Construction and Building Materials, 18(1), 9-19.

Cadei, J., Stratford, T., Hollaway, L., and Construction Industry Research \& Information Association (2004). Strengthening metallic structures using externally bonded fibre-reinforced polymers, Vol. 595. Ciria, London.

Chiew, S., Yu, Y., and Lee, C. (2011). "Bond failure of steel beams strengthened with frp laminates - part 1: Model development." Composites Part B: Engineering, 42(5), 1114-1121.

Colombi, P., Bassetti, A., and Nussbaumer, A. (2003). "Analysis of cracked steel members reinforced by pre-stress composite patch." Fatigue and Fracture of Engineering Materials and Structures, 26(1), 59-66.

Colombi, P. and Poggi, C. (2006). "Strengthening of tensile steel members and bolted joints using adhesively bonded CFRP plates." Construction and Building Materials, 20(1-2), 22-33.

Fernando, N. D. (2010). Bond Behaviour and Debonding Failures in CFRP-strengthened Steel 
Members. Department of Civil and Structural Engineering, The Hong Kong Polytechnic University.

Haghani, R. and Al-Emrani, M. (2012a). "A new design model for adhesive joints used to bond frp laminates to steel beams - part a: Background and theory." Construction and Building Materials, 34, 486-493.

Haghani, R. and Al-Emrani, M. (2012b). “A new design model for adhesive joints used to bond frp laminates to steel beams: Part b: Experimental verification." Construction and Building Materials, 30, 686-694.

Harries, K. A., Peck, A., and Abraham, E. J. (2008). "Experimental investigations of FRPstabilized steel compression members." Proceeding of the $4^{\text {th }}$ International Conference on FRP Composites in Civil Engineering, Zurich.

Harries, K. A., Peck, A. J., and Abraham, E. J. (2009). "Enhancing stability of structural steel sections using FRP.” Thin-Walled Structures, 47(10), 1092-1101.

Harris, A. F. and Beevers, A. (1999). "Effects of grit-blasting on surface properties for adhesion." International Journal of Adhesion and Adhesives, 19(6), 445-452.

Hart-Smith, L. (1973). "Adhesive-bonded double-lap joints." NASA Contractor Reports CR112235.

Hart-Smith, L. (1974). "Analysis and design of advanced composite bonded joints.” NASA Contractor Reports CR-2218.

Jones, S. C. and Civjan, S. A. (2003). "Application of fiber reinforced polymer overlays to extend steel fatigue life." Journal of Composites for Construction, 7(4), 331-338.

Lam, A., Cheng, J., Yam, M., and Kennedy, G. (2007). "Repair of steel structures by bonded carbon fibre reinforced polymer patching: Experimental and numerical study of carbon fibre reinforced polymer - steel double-lap joints under tensile loading." Canadian Journal of Civil Engineering, 34(12), 1542-1553.

Liu, H., Zhao, X.-L., Al-Mahaidi, R., and Rizkalla, S. (2005). "Analytical bond models between steel and normal modulus cfrp." Fourth International Conference on Advances in Steel Struc- 
tures, Elsevier Science Ltd, 1545 - 1552.

Mays, G. C. and Hutchinson, A. (1992). Adhesives in civil engineering. Cambridge University Press, Cambridge, UK.

Mertz, D. and Gillespie, W. (1996). "Rehabilitation of steel bridge girders through the application of advanced composites materials." Report of investigation, Transportation Research Board.

Packham, D. E. (2003). “Surface energy, surface topography and adhesion.” International Journal of Adhesion and Adhesives, 23(6), 437-448.

Photiou, N. K., Hollaway, L. C., and Chryssanthopoulos, M. K. (2006). "Strengthening of an artificially degraded steel beam utilising a carbon/glass composite system." Construction and Building Materials, 20(1-2), 11-21.

Qaidar, H. and Karunasena, W. (2010). "Use of CFRP for rehabilitation of steel structures: a review." Southern Region Engineering Conference, Toowoomba, Australia.

Rameshni, R., Arcovio, S., Green, M., and MacDougall, C. (2013). "Experimental and numerical study of adhesively bonded glass fibre-reinforced polymer - to-steel double-shear lap splices." Canadian Journal of Civil Engineering, 40(11), 1140 - 1149.

Rizkalla, S., Dawood, M., and Schnerch, D. (2008). "Development of a carbon fiber reinforced polymer system for strengthening steel structures." Composites Part A: Applied Science and Manufacturing, 39(2), 388-397.

Schnerch, D., Dawood, M., Rizkalla, S., and Sumner, E. (2007). "Proposed design guidelines for strengthening of steel bridges with FRP materials." Construction and Building Materials, 21(5), 1001-1010.

Schnerch, D., Stanford, K., Sumner, E., and Rizkalla, S. (2004). "Strengthening steel structures and bridges with high-modulus carbon fiber-reinforced polymers resin selection and scaled monopole behavior." Transportation Research Record: Journal of the Transportation Research Board, 1892(1), 237-245.

Shaat, A. and Fam, A. (2006). "Axial loading tests on short and long hollow structural steel columns retrofitted using carbon fibre reinforced polymers." Canadian Journal of Civil Engi- 
neering, 33(4), 458-470.

Tavakkolizadeh, M. and Saadatmanesh, H. (2001). "Galvanic corrosion of carbon and steel in aggressive environments.” Journal of Composites for Construction, 5(3), 200-210.

Tavakkolizadeh, M. and Saadatmanesh, H. (2003a). "Fatigue strength of steel girders strengthened with carbon fiber reinforced polymer patch.” Journal of Structural Engineering, 129(2), 186196.

Tavakkolizadeh, M. and Saadatmanesh, H. (2003b). "Repair of damaged steel-concrete composite girders using carbon fiber-reinforced polymer sheets." Journal of Composites for Construction, 7(4), 311-322.

Volkersen, O. (1938). "Die nietkraftverteilung in zugbeanspruchten nietverbindungen mit konstanten laschenguerschnitten.” Luftfahrtforschung, 15, 41 - 47.

Wang, H.-T., Wu, G., and Wu, Z.-S. (2014). "Effect of frp configurations on the fatigue repair effectiveness of cracked steel plates.” Journal of Composites for Construction, 18(1).

Yu, Y., Chiew, S., and Lee, C. (2011). "Bond failure of steel beams strengthened with frp laminates - part 2: Verification.” Composites Part B: Engineering, 42(5), 1122-1134.

Zhao, X. and Zhang, L. (2007). "State-of-the-art review on FRP strengthened steel structures." Engineering Structures, 29(8), 1808-1823. 
The following symbols are used in this paper:

$$
\begin{aligned}
& A_{f}=\text { cross sectional area of CFRP } \\
& A_{g}=\text { gross cross sectional area of steel } \\
& A_{n}=\text { net cross sectional area of steel } \\
& A_{t}=\text { total cross section area of steel plate with CFRP } \\
& b_{c}=\text { width of CFRP strip } \\
& b_{s}=\text { width of steel element } \\
& C_{i}=\text { hole configuration with } i=1,2,3 \text { where } C_{1}=\text { two holes staggered, } C_{2}=\text { two } \\
& \text { holes side by side and } C_{3}=\text { one hole centered; see Figure } 3.8 \\
& d=\text { bolt diameter } \\
& E=\text { elastic modulus } \\
& E_{f}=\text { elastic modulus of CFRP } \\
& E_{i}=\text { Young's modulus of the inner adherend layer } \\
& E_{o}=\text { Young's modulus of the outer adherend layer } \\
& E_{s}=\text { elastic modulus of steel } \\
& F_{\text {debonding }}=\text { debonding load of CFRP } \\
& f_{y}=\text { yield stress of steel } \\
& F_{e l}=\text { elastic force of specimen } \\
& F_{e l}^{r e f}=\text { elastic force of specimen without CFRP } \\
& G_{a}=\text { adhesive shear modulus } \\
& G_{f}=\text { fracture energy } \\
& G_{p}=\text { strain energy release rate at the elastic limit } \\
& H_{s}=\text { steel hardening modulus } \\
& L_{c}=\text { length of CFRP strip } \\
& L_{e}=\text { effective bond length } \\
& L_{L}=\text { anchor length of CFRP } \\
& L_{s}=\text { length of steel plate }
\end{aligned}
$$




$$
\begin{aligned}
& N_{p}=\text { number of layer of CFRP sheet } \\
& P_{i}=\text { bond strength of inner adherend } \\
& P_{o}=\text { bond strength of outer adherend } \\
& P_{C F R P}=\text { load carrying capacity of the CFRP } \\
& P_{f}^{e l-p l}=\text { elastoplastic debonding strength } \\
& P_{y}=\text { yield force } \\
& P_{u l t}=\text { ultimate load carrying capacity per unit width } \\
& S i=\text { steel surface preparation with } i=1,2,3 \text { where } S 1=\text { sandpaper, } \\
& S 2=\text { abrasive disk and } S 3=\text { steel brush } \text {. } \\
& t_{a}=\text { adhesive thickness } \\
& t_{c}=\text { thickness of CFRP strip } \\
& t_{i}=\text { thickness of inner adherend layer } \\
& t_{o}=\text { thickness of outer adherend layer } \\
& t_{s}=\text { thickness of steel element } \\
& \gamma_{e}=\text { elastic adhesive shear strain } \\
& \gamma_{p}=\text { plastic adhesive shear strain } \\
& \delta=\text { unbalance stiffness between adherents } \\
& \delta_{\text {debonding }}=\text { displacement at debonding } \\
& \delta_{e l}=\text { displacement at elastic force } \\
& \lambda=\text { coefficient of elastic shear stress distribution } \\
& \sigma_{u l t}=\text { ultimate strength of steel plate } \\
& \tau_{p}=\text { adhesive shear strength } \\
& \phi h=\text { hole diameter }
\end{aligned}
$$




\section{List of Tables}

1 Material properties of steel plates, CFRP and epoxy $\ldots \ldots 22$

2 Dimensions of the specimens for anchor length study $\ldots \ldots$

3 Double lap joint test results $\quad \ldots \ldots \ldots \ldots$. . . . . 24

4 Steel plates specimen's results $\quad \ldots \ldots \ldots \ldots$

5 Theoretical and experimental values for the elastic and ultimate limits . . . . . 26

6 Phase III results $\ldots \ldots \ldots \ldots \ldots$ 
TABLE 1. Material properties of steel plates, CFRP and epoxy

\begin{tabular}{lccc}
\hline & $\begin{array}{c}\text { Elastic modulus } \\
(\mathrm{MPa})\end{array}$ & $\begin{array}{c}\text { Yield strength } \\
(\mathrm{MPa})\end{array}$ & $\begin{array}{c}\text { Ultimate strength } \\
(\mathrm{MPa})\end{array}$ \\
\hline Steel plate & 203000 & 384 & 537 \\
Foreva TFC & 230000 & - & 4900 \\
Foreva Epx TFC & 2300 & - & 27 \\
Sika Carbodur S1525 & 165000 & - & 2800 \\
Sikadur 330 & 4500 & - & 30 \\
\hline
\end{tabular}


TABLE 2. Dimensions of the specimens for anchor length study

\begin{tabular}{|c|c|c|c|c|c|c|c|}
\hline \multirow{2}{*}{ Specimen } & \multicolumn{2}{|c|}{ Steel element geometry } & \multicolumn{3}{|c|}{ CFRP strip geometry } & \multirow{2}{*}{$L_{L}(m m)$} & \multirow{2}{*}{$\mathrm{S} i$} \\
\hline & $L_{s}(m m)$ & $b_{s}(m m)$ & $L_{c}(m m)$ & $b_{c}(m m)$ & $t_{c}(m m)$ & & \\
\hline S-100-S1 & 250 & 100 & 200 & 90 & 0.48 & 100 & $\mathrm{~S} 1$ \\
\hline S-150-S1 & 300 & 100 & 300 & 90 & 0.48 & 150 & $\mathrm{~S} 1$ \\
\hline S-200-S1 & 350 & 100 & 400 & 90 & 0.48 & 200 & $\mathrm{~S} 1$ \\
\hline S-100-S2 & 250 & 100 & 200 & 90 & 0.48 & 100 & $\mathrm{~S} 2$ \\
\hline S-150-S2 & 300 & 100 & 300 & 90 & 0.48 & 150 & $\mathrm{~S} 2$ \\
\hline S-200-S2 & 350 & 100 & 400 & 90 & 0.48 & 200 & $\mathrm{~S} 2$ \\
\hline S-100-S3 & 250 & 100 & 200 & 90 & 0.48 & 100 & $\mathrm{~S} 3 \dagger$ \\
\hline S-150-S3 & 300 & 100 & 300 & 90 & 0.48 & 150 & $\mathrm{~S} 3 \dagger$ \\
\hline S-200-S3 & 350 & 100 & 400 & 90 & 0.48 & 200 & $\mathrm{~S} 3 \dagger$ \\
\hline P-100-S1 & 250 & 32 & 200 & 15 & 2.50 & 100 & $\mathrm{~S} 1$ \\
\hline P-150-S1 & 300 & 32 & 300 & 15 & 2.50 & 150 & $\mathrm{~S} 1$ \\
\hline P-200-S1 & 350 & 32 & 400 & 15 & 2.50 & 200 & $\mathrm{~S} 1$ \\
\hline P-100-S2 & 250 & 32 & 200 & 15 & 2.50 & 100 & $\mathrm{~S} 2$ \\
\hline P-150-S2 & 300 & 32 & 300 & 15 & 2.50 & 150 & $\mathrm{~S} 2$ \\
\hline P-200-S2 & 350 & 32 & 400 & 15 & 2.50 & 200 & $\mathrm{~S} 2$ \\
\hline P-100-S3 & 250 & 32 & 200 & 15 & 2.50 & 100 & $\mathrm{~S} 3 \dagger$ \\
\hline P-150-S3 & 300 & 32 & 300 & 15 & 2.50 & 150 & $\mathrm{~S} 3 \dagger$ \\
\hline P-200-S3 & 350 & 32 & 400 & 15 & 2.50 & 200 & $\mathrm{~S} 3 \dagger$ \\
\hline
\end{tabular}

Designation of specimens: $\mathrm{S}($ or $\mathrm{P})-L_{L}-S_{i}$ means $\mathrm{S}=$ sheet, $\mathrm{P}=$ plate, $L_{L}=$ anchor length and $\mathrm{S} i=$ surface preparation with $i=1,2,3$ where $\mathrm{S} 1=$ sandpaper, $\mathrm{S} 2=$ abrasive disk and $\mathrm{S} 3=$ steel brush.

$\dagger$ Galvanized steel 
TABLE 3. Double lap joint test results

\begin{tabular}{|c|c|c|c|c|c|}
\hline Specimen & $\begin{array}{l}\text { Ultimate } \\
\text { load }(\mathrm{kN})\end{array}$ & Specimen & $\begin{array}{l}\text { Ultimate } \\
\text { load }(\mathrm{kN})\end{array}$ & Specimen & $\begin{array}{l}\text { Ultimate } \\
\operatorname{load}(\mathrm{kN})\end{array}$ \\
\hline S-100-S1 \#1 & 45.8 & S-100-S2 \#1 & 55.9 & S-100-S3 \#1 & 39.6 \\
\hline S-100-S1 \#2 & 42.3 & S-100-S2 \#2 & 63.7 & S-100-S3 \#2 & 37.6 \\
\hline S-150-S1 \#1 & 46.9 & S-150-S2 \#1 & 78.0 & S-150-S3 \#1 & 35.7 \\
\hline S-150-S1 \#2 & 42.5 & S-150-S2 \#2 & 70.9 & S-150-S3 \#2 & 38.6 \\
\hline S-200-S1 \#1 & 49.4 & S-200-S2 \#1 & 59.8 & S-200-S3 \#1 & 40.8 \\
\hline S-200-S1 \#2 & 45.2 & S-200-S2 \#2 & 63.2 & S-200-S3 \#2 & 41.2 \\
\hline Average & 45.4 & Average & 65.3 & Average & 38.9 \\
\hline P-100-S1 \#1 & 19.8 & P-100-S2 \#1 & 49.2 & P-100-S3 \#1 & 28.0 \\
\hline P-100-S1 \#2 & 20.4 & $\mathrm{P}-100-\mathrm{S} 2$ \#2 & 47.9 & P-100-S3 \#2 & 20.9 \\
\hline P-150-S1 \#1 & 24.7 & P-150-S2 \#1 & 59.0 & P-150-S3 \#1 & 35.8 \\
\hline P-150-S1 \#2 & 29.2 & $\mathrm{P}-150-\mathrm{S} 2$ \#2 & 50.8 & P-150-S3 \#2 & 21.7 \\
\hline P-200-S1 \#1 & 25.4 & P-200-S2 \#1 & 40.4 & P-200-S3 \#1 & 27.3 \\
\hline P-200-S1 \#2 & 28.9 & $\mathrm{P}-200-\mathrm{S} 2$ \#2 & 43.5 & P-200-S3 \#2 & 33.5 \\
\hline Average & 24.7 & Average & 48.5 & Average & 27.9 \\
\hline
\end{tabular}


TABLE 4. Steel plates specimen's results

\begin{tabular}{|c|c|c|c|c|c|c|c|}
\hline Specimen & $L_{L}(m m)$ & $d(m m)$ & $\frac{A_{n}}{A_{g}}(\%)$ & $F_{e l}(k N)$ & $\delta_{e l}(m m)$ & $\begin{array}{l}F_{\text {debonding }} \delta_{d e} \\
(k N)\end{array}$ & $\begin{array}{l}\text { debonding } \\
(\mathrm{mm})\end{array}$ \\
\hline C1-150-B16 \#1 & 150 & 15.9 & 75 & 177 & 1.41 & 213 & 3.09 \\
\hline C1-150-B16 \#2 & 150 & 15.9 & 75 & 177 & 1.44 & 215 & 3.11 \\
\hline C1-225-B16 \#1 & 225 & 15.9 & 75 & 173 & 1.36 & 220 & 3.96 \\
\hline C1-225-B16 \#2 & 225 & 15.9 & 75 & 172 & 1.37 & 189 & 2.04 \\
\hline C1-B16 \#1 & - & 15.9 & 75 & 163 & 1.36 & - & - \\
\hline C1-B16 \#2 & - & 15.9 & 75 & 163 & 1.26 & - & - \\
\hline C1-150-B22 \#1 & 150 & 22.2 & 62 & 147 & 1.18 & 195 & 4.52 \\
\hline C1-150-B22 \#2 & 150 & 22.2 & 62 & 147 & 1.15 & 196 & 4.53 \\
\hline C1-225-B22 \#1 & 225 & 22.2 & 62 & 146 & 1.39 & 200 & 7.50 \\
\hline C1-225-B22 \#2 & 225 & 22.2 & 62 & 146 & 1.15 & 190 & 4.13 \\
\hline C1-B22 \#1 & - & 22.2 & 62 & 135 & 1.04 & - & - \\
\hline C1-B22 \#2 & - & 22.2 & 62 & 138 & 1.06 & - & - \\
\hline C2-150-B16 \#1 & 150 & 15.9 & 65 & 158 & 1.27 & 210 & 2.96 \\
\hline C2-150-B16 \#2 & 150 & 15.9 & 65 & 158 & 1.25 & 207 & 2.85 \\
\hline C2-225-B16 \#1 & 225 & 15.9 & 65 & 158 & 1.29 & 211 & 3.16 \\
\hline C2-225-B16 \#2 & 225 & 15.9 & 65 & 158 & 1.27 & 209 & 2.99 \\
\hline C2-B16 \#1 & - & 15.9 & 65 & 151 & 1.23 & - & - \\
\hline C2-B16 \#2 & - & 15.9 & 65 & 152 & 1.19 & - & - \\
\hline C2-150-B22 \#1 & 150 & 22.2 & 52 & 128 & 1.03 & 182 & 4.24 \\
\hline C2-150-B22 \#2 & 150 & 22.2 & 52 & 125 & 1.07 & 181 & 4.20 \\
\hline C2-225-B22 \#1 & 225 & 22.2 & 52 & 128 & 1.02 & 191 & 5.51 \\
\hline C2-225-B22 \#2 & 225 & 22.2 & 52 & 127 & 1.05 & 189 & 5.69 \\
\hline C2-B22 \#1 & - & 22.2 & 52 & 122 & 1.04 & - & - \\
\hline C2-B22 \#2 & - & 22.2 & 52 & 121 & 1.02 & - & - \\
\hline C3-150-B16 \#1 & 150 & 15.9 & 83 & 199 & 1.69 & 206 & 2.24 \\
\hline C3-150-B16 \#2 & 150 & 15.9 & 83 & 202 & 1.75 & 227 & 3.14 \\
\hline C3-225-B16 \#1 & 225 & 15.9 & 83 & 203 & 1.72 & 230 & 3.40 \\
\hline C3-225-B16 \#2 & 225 & 15.9 & 83 & 193 & 1.54 & 218 & 3.33 \\
\hline C3-B16 \#1 & - & 15.9 & 83 & 187 & 1.61 & - & - \\
\hline C3-B16 \#1 & - & 15.9 & 83 & 187 & 1.67 & - & - \\
\hline C3-150-B22 \#1 & 150 & 22.2 & 76 & 172 & 1.64 & 213 & 6.06 \\
\hline C3-150-B22 \#2 & 150 & 22.2 & 76 & 173 & 1.64 & 211 & 5.63 \\
\hline C3-225-B22 \#1 & 225 & 22.2 & 76 & 172 & 1.71 & 213 & 6.61 \\
\hline C3-225-B22 \#2 & 225 & 22.2 & 76 & 185 & 1.70 & 222 & 3.62 \\
\hline C3-B22 \#1 & - & 22.2 & 76 & 169 & 1.30 & - & - \\
\hline C3-B22 \#2 & - & 22.2 & 76 & 171 & 1.26 & - & - \\
\hline
\end{tabular}

Designation of specimens: $C_{i}-L_{L}-B d$ means $C_{i}=$ configuration with $i=1,2,3$ where $C_{1}=$ two holes staggered, $C_{2}=$ two holes side by side and $C_{3}=$ one hole centered, $L_{L}=$ anchor length and $B d=$ bolt diameter in millimeters. 
TABLE 5. Theoretical and experimental values for the elastic and ultimate limits

\begin{tabular}{cccccc}
\hline Specimen & $A_{n} / A_{g}(\%)$ & $F_{\text {el }}^{r e f}(\mathrm{kN})$ & $f_{y} A_{n}(\mathrm{kN})$ & $F_{u}^{r e f}(\mathrm{kN})$ & $\sigma_{u l t} A_{n}(\mathrm{kN})$ \\
\hline C1-B16 & 75 & 163 & 173 & 237 & 242 \\
C2-B16 & 65 & 151 & 150 & 217 & 210 \\
C3-B16 & 83 & 187 & 190 & 264 & 266 \\
C1-B22 & 62 & 137 & 144 & 200 & 201 \\
C2-B22 & 52 & 121 & 121 & 170 & 169 \\
C3-B22 & 76 & 170 & 176 & 247 & 245 \\
\hline
\end{tabular}


TABLE 6. Phase III results

\begin{tabular}{lccccc}
\hline Specimen & $L_{L}(\mathrm{~mm})$ & $N_{p}$ & $S_{i}$ & $F_{\text {debonding }}(k N)$ & $F_{\text {el }}(k N)$ \\
\hline C3-S-1-150-S3 \#1 & 150 & 1 & $\mathrm{~S} 3$ & 213 & 171 \\
C3-S-1-150-S3 \#2 & 150 & 1 & $\mathrm{~S} 3$ & 211 & 170 \\
C3-S-1-225-S3 \#1 & 225 & 1 & $\mathrm{~S} 3$ & 213 & 171 \\
C3-S-1-225-S3 \#2 & 225 & 1 & $\mathrm{~S} 3$ & 222 & 177 \\
C3-S-1-150-S2 \#1 & 150 & 1 & $\mathrm{~S} 2$ & 226 & 182 \\
C3-S-1-150-S2 \#2 & 150 & 1 & $\mathrm{~S} 2$ & 229 & 181 \\
C3-S-1-225-S2 \#1 & 225 & 1 & $\mathrm{~S} 2$ & 234 & 186 \\
C3-S-1-225-S2 \#2 & 225 & 1 & $\mathrm{~S} 2$ & 239 & 185 \\
C3-S-1-150-S2p \#1 & 150 & 1 & $\mathrm{~S} 2$ (partially) & 230 & 187 \\
C3-S-1-150-S2p \#2 & 150 & 1 & $\mathrm{~S} 2$ (partially) & 231 & 184 \\
C3-D-1-150-S3 & 150 & 1 & $\mathrm{~S} 3$ & 213 & 194 \\
C3-D-1-150-S2 & 150 & 1 & $\mathrm{~S} 2$ & 221 & 199 \\
C3-D-2-taper-S3 & 150,170 & 2 & $\mathrm{~S} 3$ & 201 & 199 \\
C3-D-2-taper-S2 & 150,170 & 2 & $\mathrm{~S} 2$ & 226 & 223 \\
C3-S-2-taper1-S3 \#1 & 150,250 & 2 & $\mathrm{~S} 3$ & 211 & 190 \\
C3-S-2-taper1-S3 \#2 & 150,250 & 2 & $\mathrm{~S} 3$ & 222 & 190 \\
C3-S-2-taper1-S2 \#1 & 150,250 & 2 & $\mathrm{~S} 2$ & 226 & 193 \\
C3-S-2-taper1-S2 \#2 & 150,250 & 2 & $\mathrm{~S} 2$ & 215 & 196 \\
C3-S-2-taper2-S3 & 150,170 & 2 & $\mathrm{~S} 3$ & 208 & 185 \\
C3-S-4-taper-S3 & $150,170,190,210$ & 4 & $\mathrm{~S} 3$ & 194 & 187 \\
C3-S-6-taper-S3 & $150,170,190,210,230,250$ & 6 & $\mathrm{~S} 3$ & 197 & 190 \\
C3-S-2-taper2-S2 & 150,170 & 2 & $\mathrm{~S} 2$ & 227 & 182 \\
C3-S-4-taper-S2 & $150,170,190,210$ & 4 & $\mathrm{~S} 2$ & 225 & 203 \\
C3-S-6-taper-S2 & $150,170,190,210,230,250$ & 6 & $\mathrm{~S} 2$ & 224 & 207 \\
C3-S-4-210-S2 \#1 & 210 & 4 & $\mathrm{~S} 2$ & 217 & 201 \\
C3-S-4-210-S2 \#2 & 210 & 4 & $\mathrm{~S} 2$ & 207 & 200 \\
C3-B22 \#1 & - & 0 & - & - & 169 \\
C3-B22 \#2 & - & 0 & - & - & 171 \\
\hline Desin & & & & \\
\end{tabular}

Designation of specimens: $C 3-S / D-N p-L_{L}-S_{i}$ means $C 3=$ one hole centered, $S / D=$ one side or two side reinforcement, $N p=$ number of CFRP layers, $L_{L}=$ anchor length or taper if many layers attached and $S_{i}=$ surface preparation with $i=1,2,3$ where $\mathrm{S} 1=$ sandpaper, $\mathrm{S} 2=$ abrasive disk and $\mathrm{S} 3=$ steel brush. 


\section{List of Figures}

1 Typical double lap joint specimen. . . . . . . . . . . . . . . . . . . 29

2 Steel plates specimens reinforced with one layer of CFRP sheet. . . . . . . . . . 30

3 Steel plate specimens phase III. . . . . . . . . . . . . . . . . 31

4 Failure modes. . . . . . . . . . . . . . . . . . . . 32

5 Maximum axial load capacity vs lap length with different surface preparation for CFRP sheets-steel double lap joints. . . . . . . . . . . . . . . . . 33

6 Maximum axial load capacity vs lap length with different surface preparation for CFRP plates-steel double lap joints. . . . . . . . . . . . . . . . . 34

7 Axial load vs displacement for two holes staggered configuration with and without CFRP reinforcement. . . . . . . . . . . . . . . . . 35

8 Axial load vs displacement for two hole in a row configuration with and without CFRP reinforcement. . . . . . . . . . . . . . . . . 36

9 Axial load vs displacement for one center hole configuration with and without CFRP reinforcement. . . . . . . . . . . . . . . . . . 37

10 Ratio between the elastic force of steel plates with CFRP and the elastic limit of steel plates alone vs $A_{n} / A_{g} \ldots \ldots \ldots \ldots$. . . . . . . . . . . . 38

11 Ratio between the debonding force of steel plates with CFRP and the elastic limit of steel plates alone vs $A_{n} / A_{g} \ldots \ldots \ldots \ldots$

12 Ratio between the debonding and elastic force of reinforced steel plates vs Number of CFRP layers. . . . . . . . . . . . . . . . . . . . . . 40

13 Ratio between the elastic force of steel plates with and without reinforcement vs number of CFRP layers. . . . . . . . . . . . . . . . . . 41 


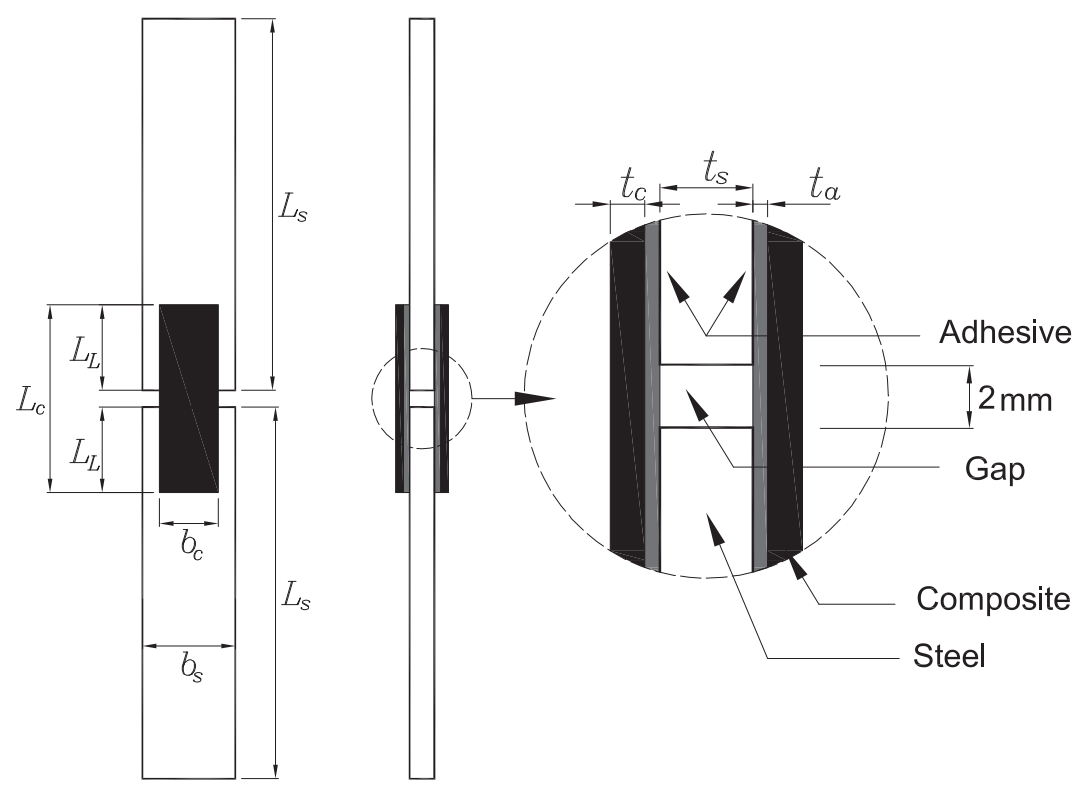

FIG. 1. Typical double lap joint specimen. 


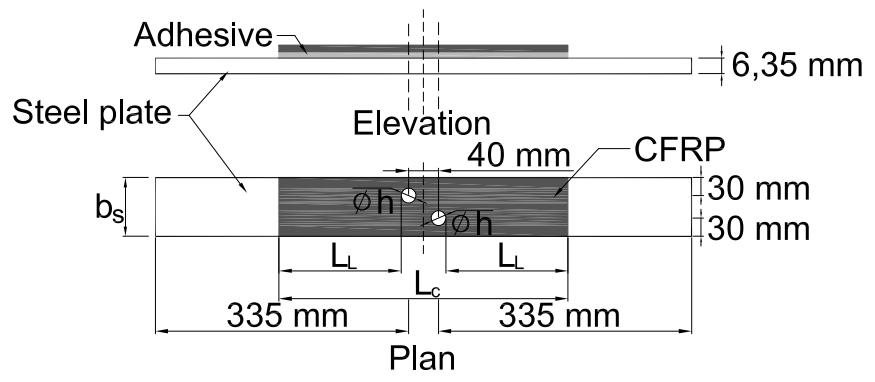

(a) Configuration 1

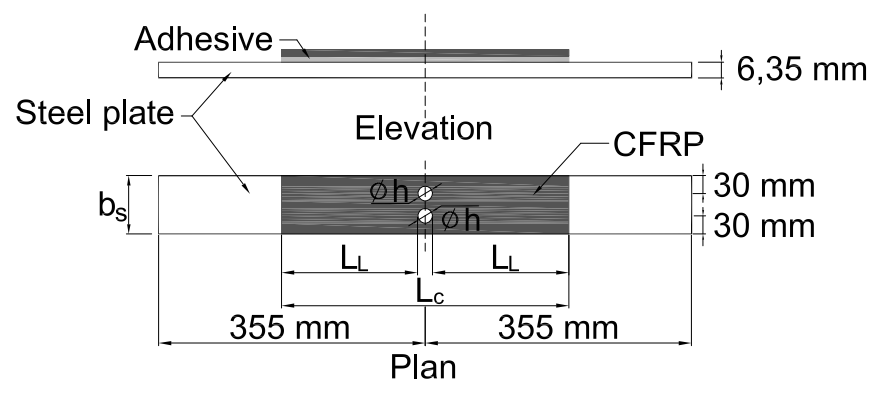

(b) Configuration 2

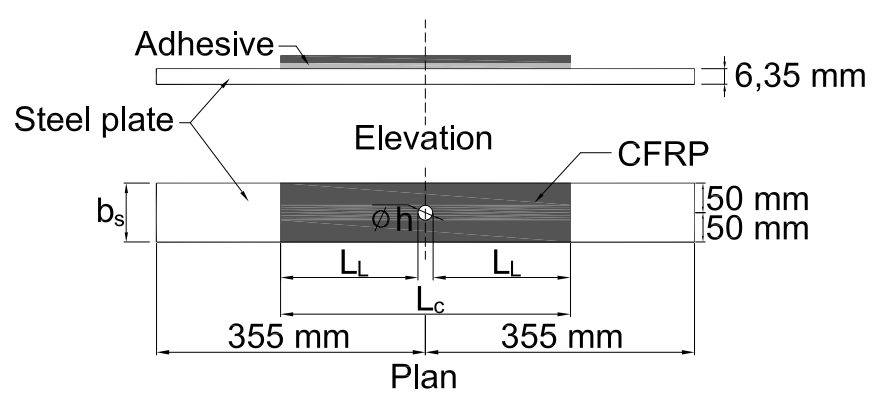

(c) Configuration 3

FIG. 2. Steel plates specimens reinforced with one layer of CFRP sheet. 


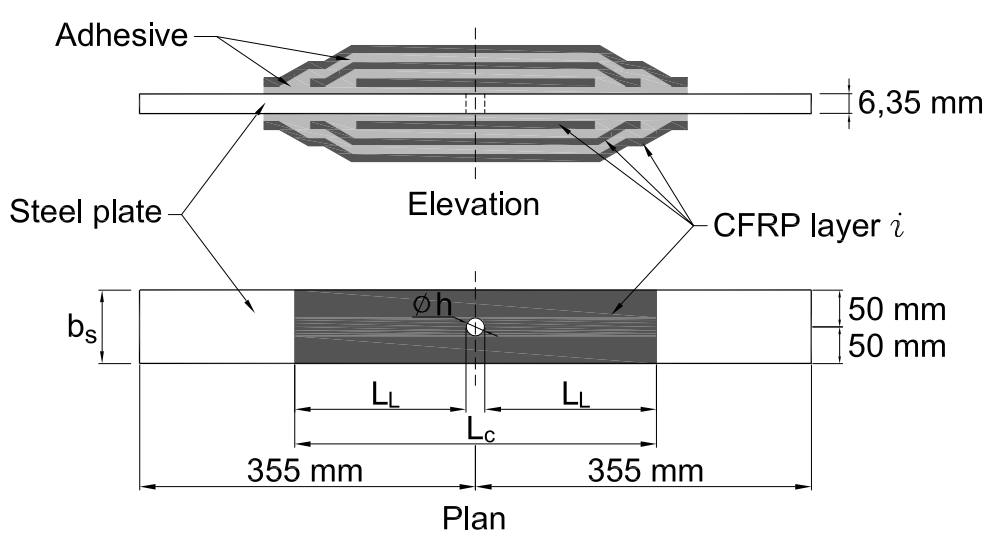

(a) Double side reinforcement.

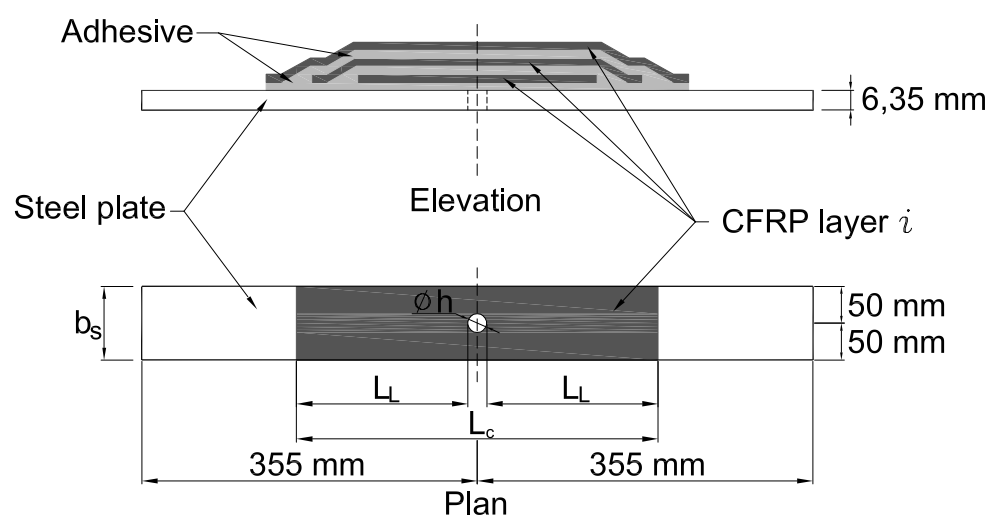

(b) Single side reinforcement.

FIG. 3. Steel plate specimens phase III. 


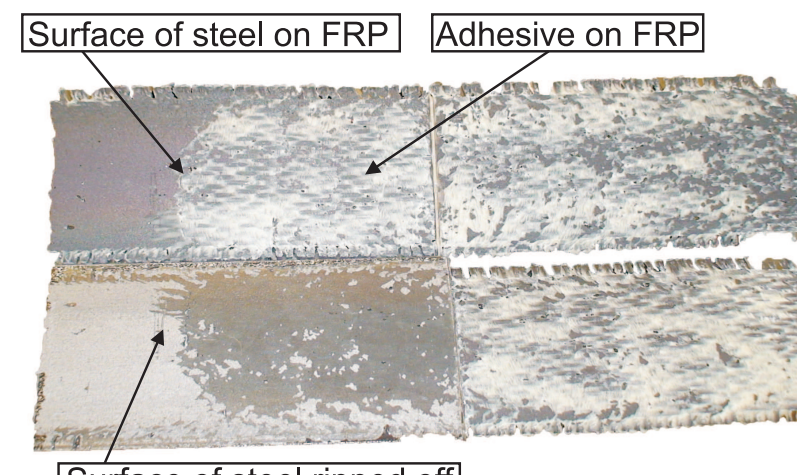

Surface of steel ripped off

(a) Sanded double lap joint specimens
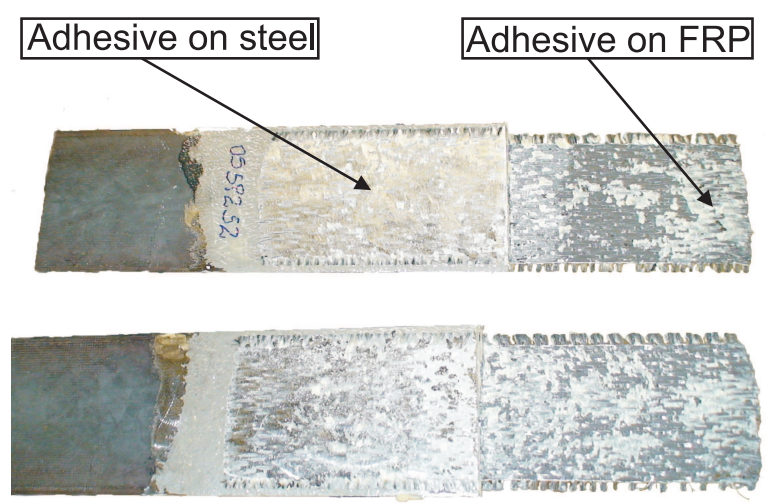

(b) Grinded double lap joint specimens

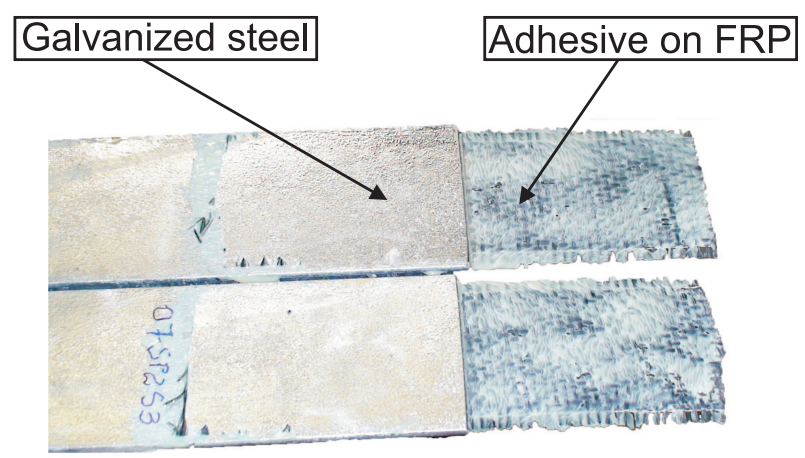

(c) Galvanized double lap joint specimens

FIG. 4. Failure modes. 


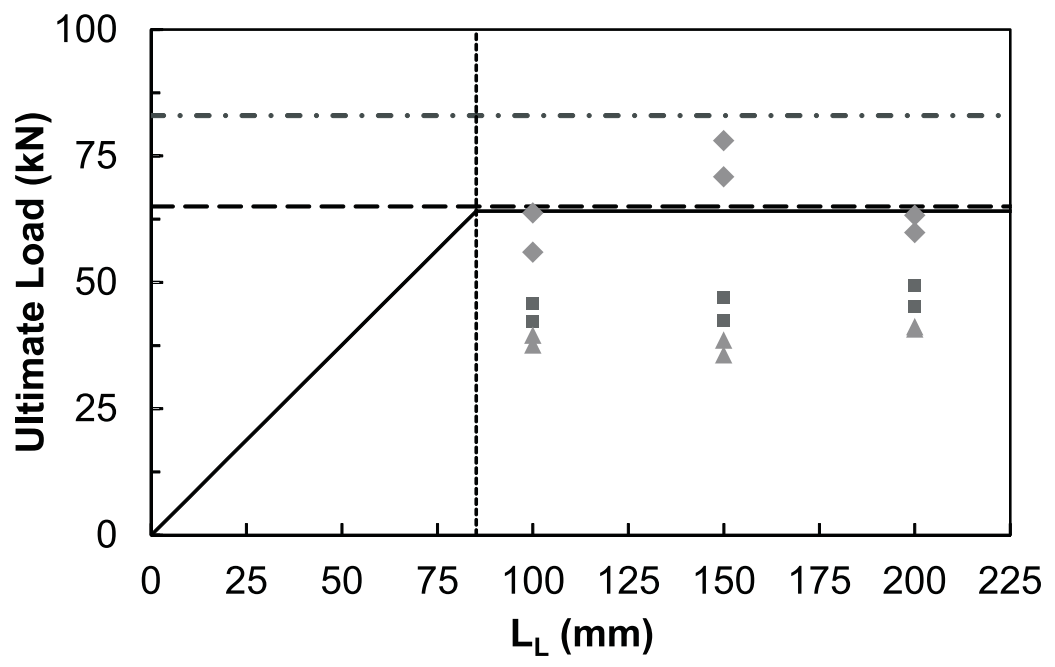

\begin{tabular}{|c|c|}
\hline S1 (Sandpaper) & S2 (Abrasive disk) \\
\hline A S3 (Galvanized Steel) & — Hart-Smith Model \\
\hline - - Bocciarelli-Colombi $(\mathrm{G} f=0.815 \mathrm{~N} / \mathrm{mm})$ & - -Bocciarelli-Colombi $(\mathrm{G} f=0.500 \mathrm{~N} / \mathrm{mm})$ \\
\hline
\end{tabular}

FIG. 5. Maximum axial load capacity vs lap length with different surface preparation for CFRP sheets-steel double lap joints. 


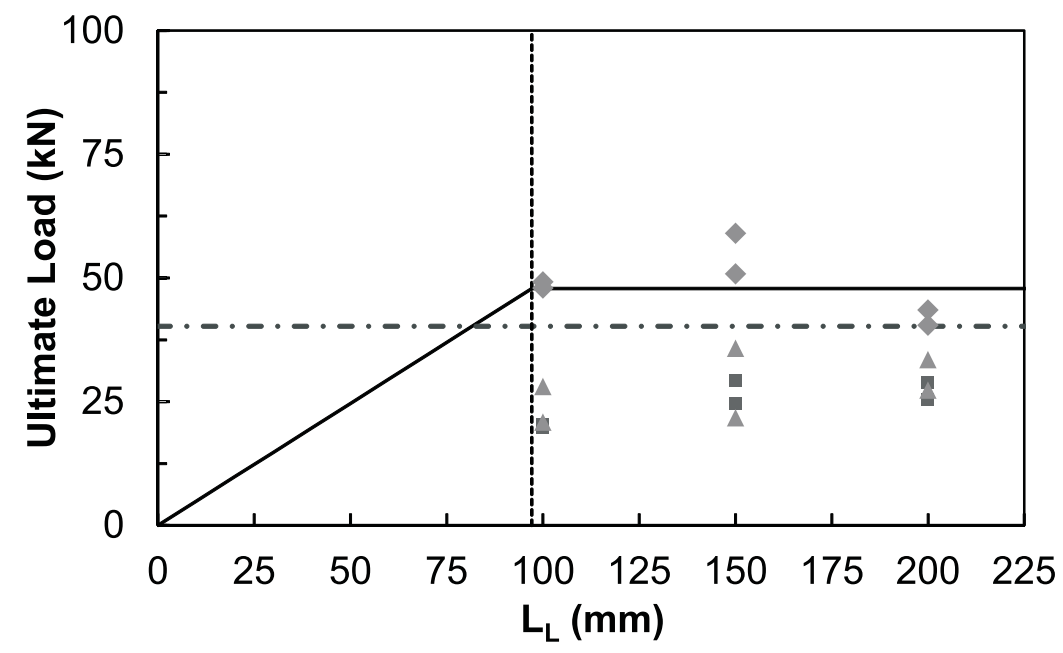
- S1 (Sandpaper)
- S2 (Abrasive disk)
- S3 (Galvanized Steel)
- Hart-Smith Model
- - Bocciarelli-Colombi $(\mathrm{G} f=0.815 \mathrm{~N} / \mathrm{mm})$
-----. Effective Length

FIG. 6. Maximum axial load capacity vs lap length with different surface preparation for CFRP plates-steel double lap joints. 


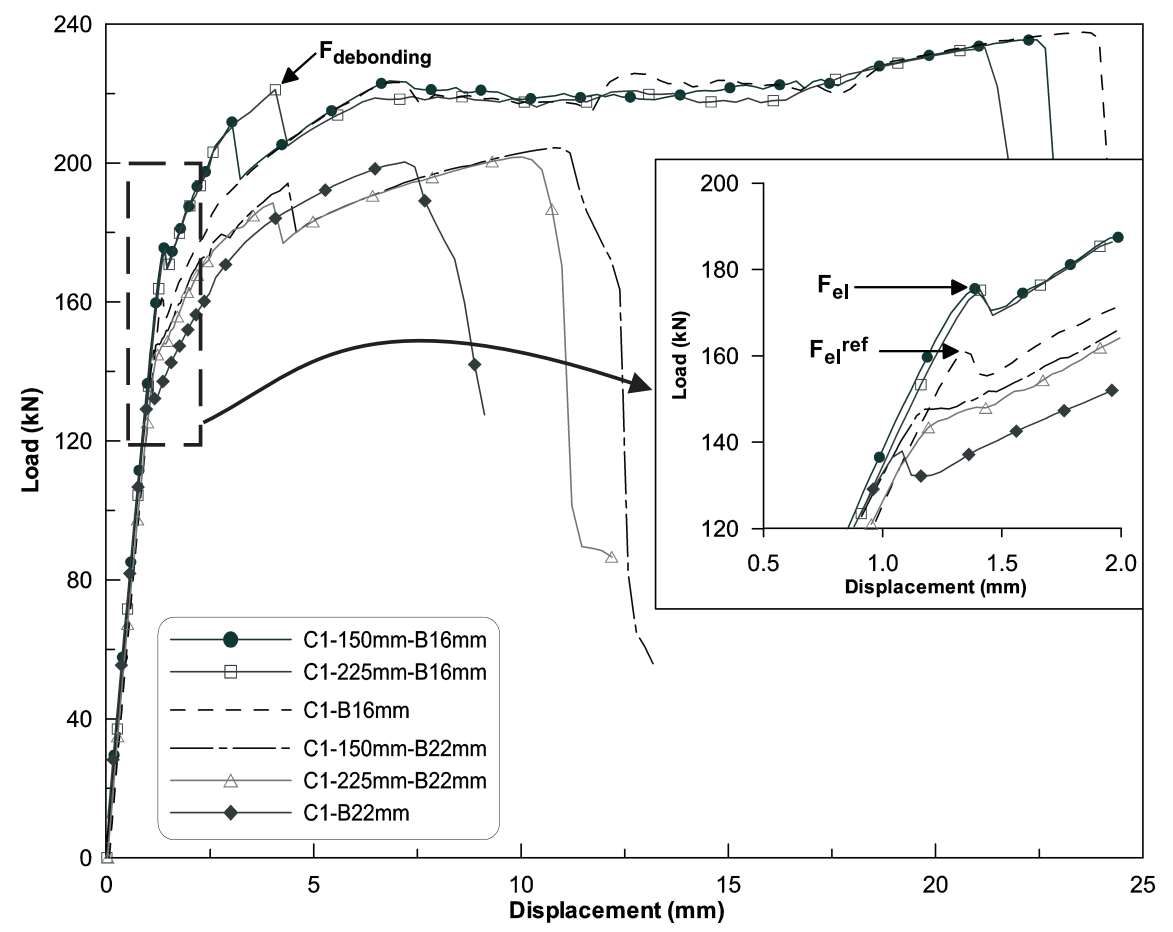

FIG. 7. Axial load vs displacement for two holes staggered configuration with and without CFRP reinforcement. 


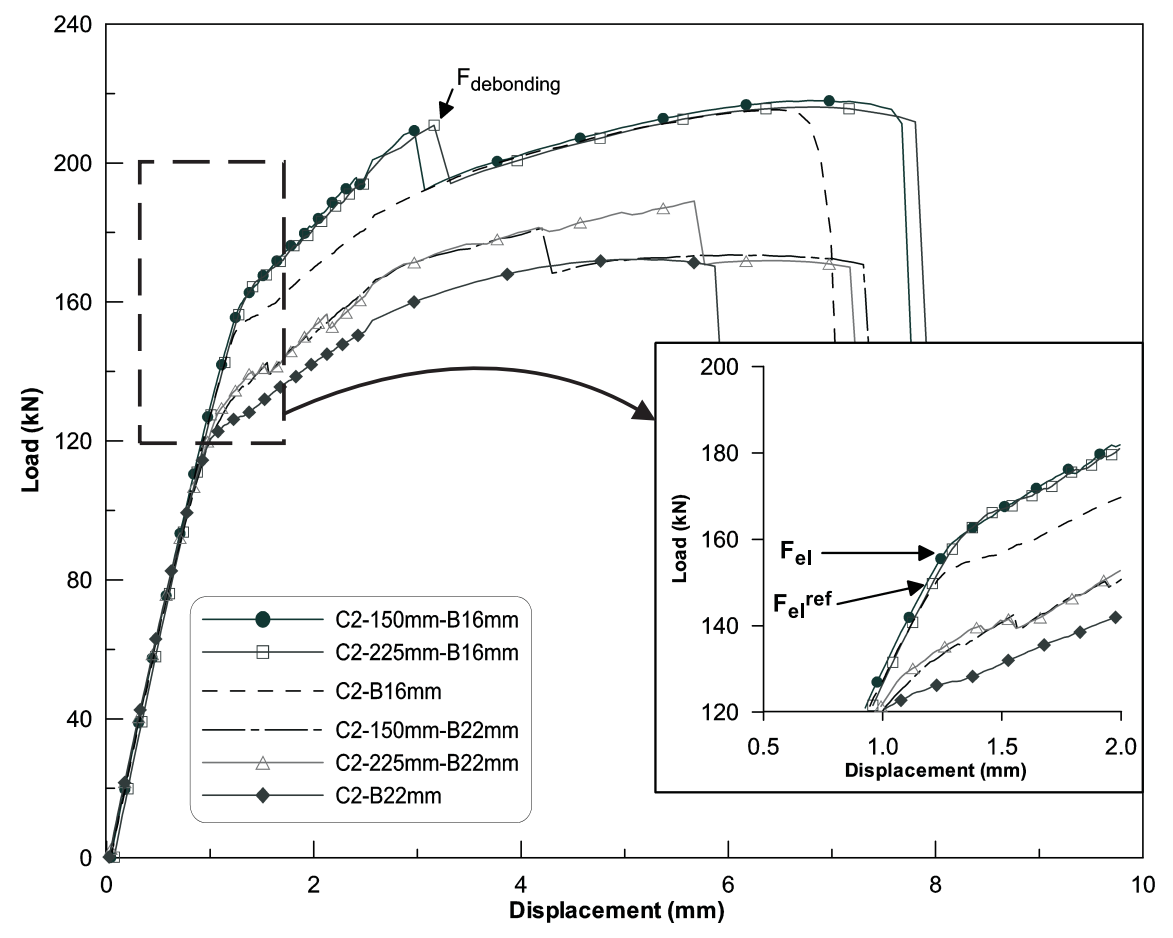

FIG. 8. Axial load vs displacement for two hole in a row configuration with and without CFRP reinforcement. 


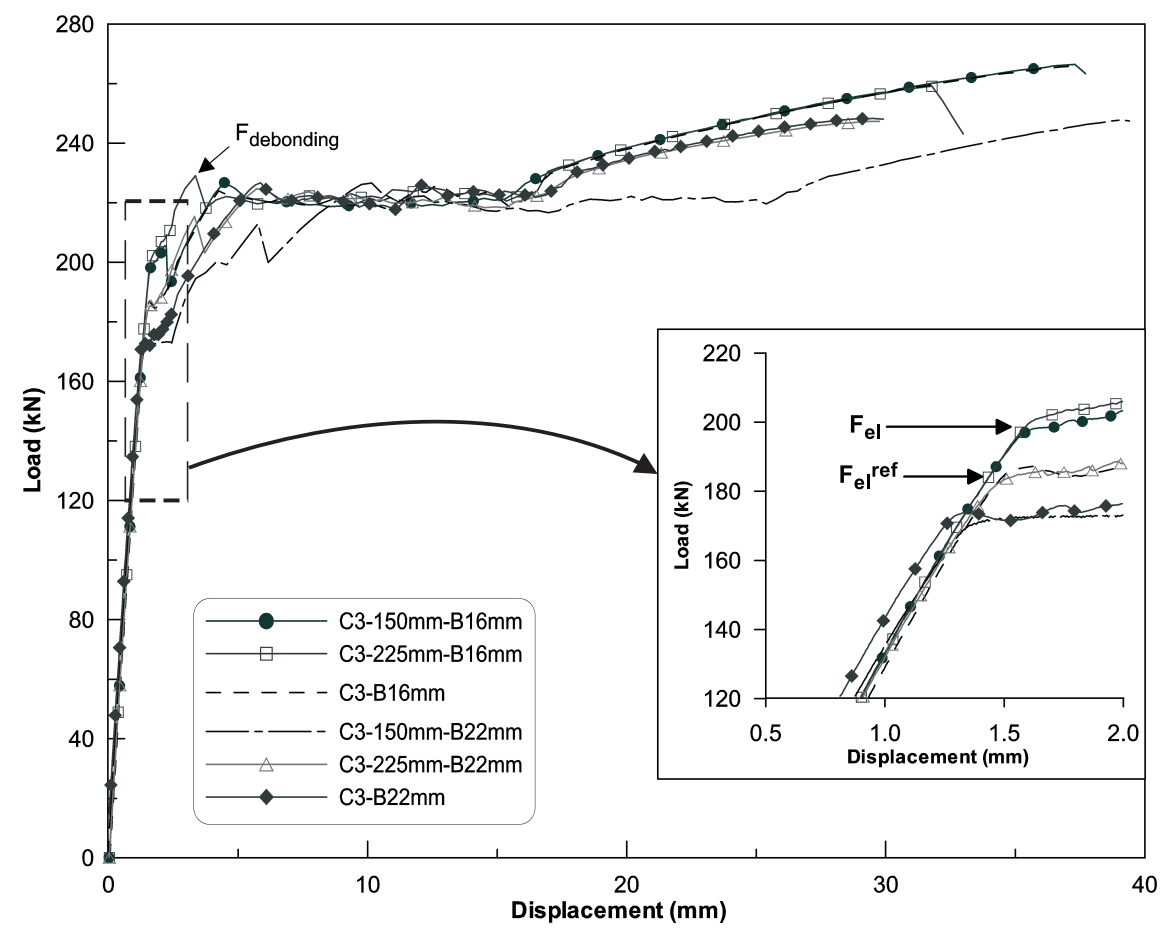

FIG. 9. Axial load vs displacement for one center hole configuration with and without CFRP reinforcement. 


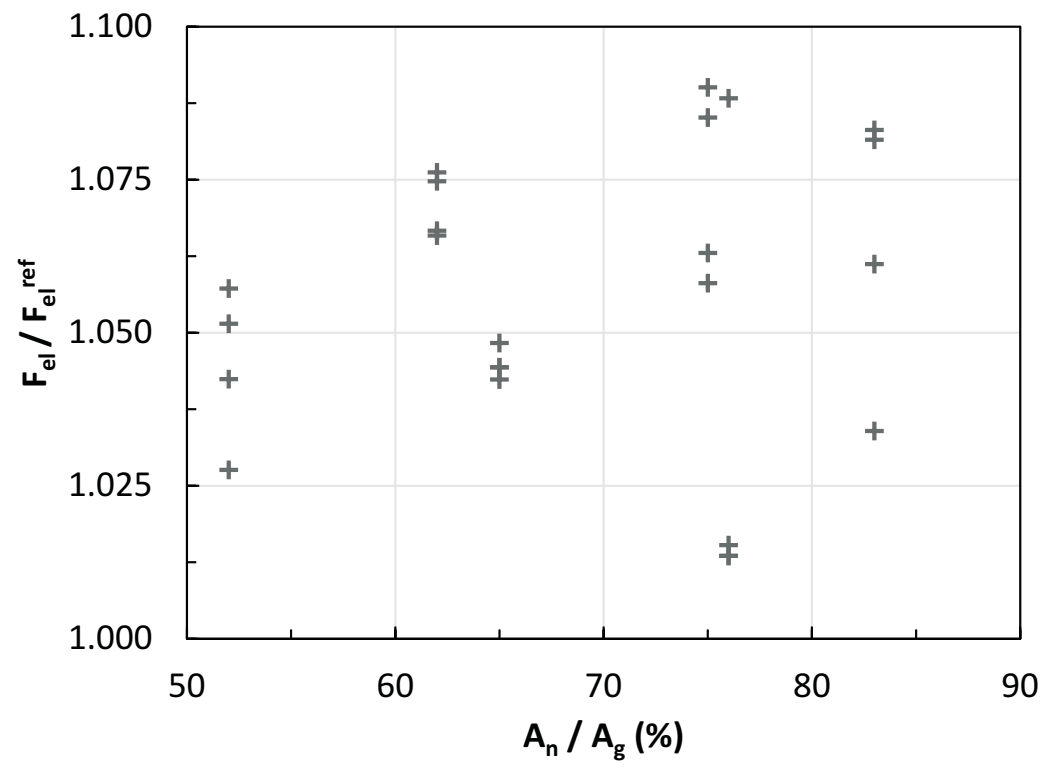

FIG. 10. Ratio between the elastic force of steel plates with CFRP and the elastic limit of steel plates alone vs $A_{n} / A_{g}$. 


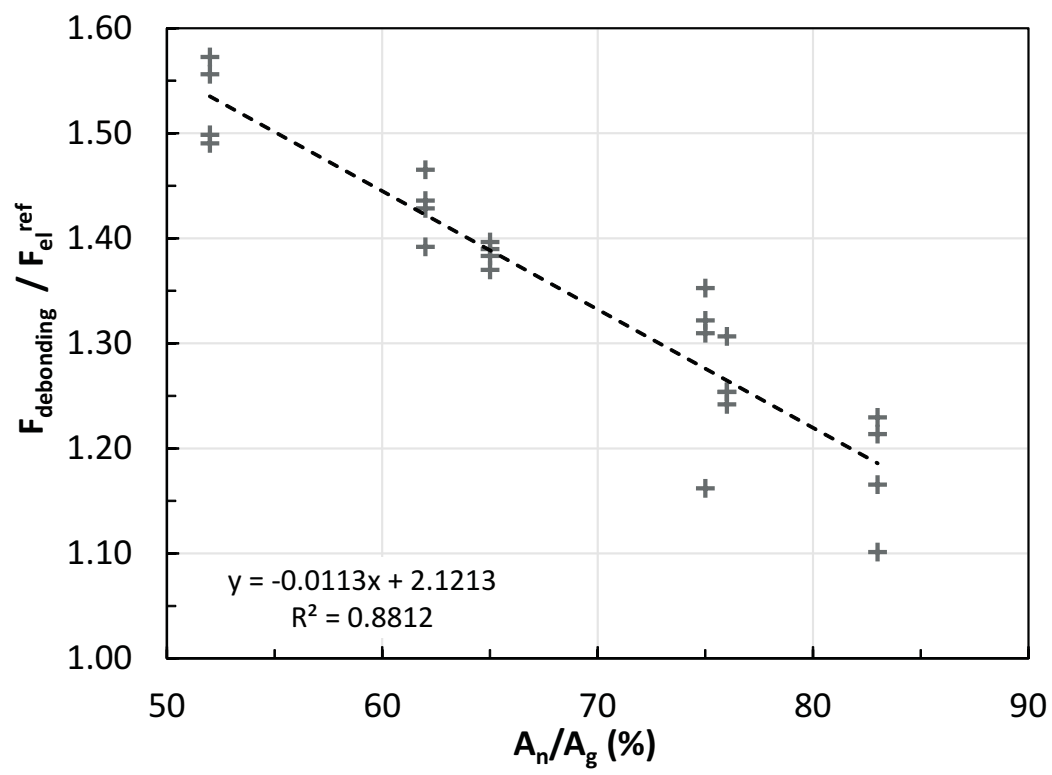

FIG. 11. Ratio between the debonding force of steel plates with CFRP and the elastic limit of steel plates alone vs $A_{n} / A_{g}$. 


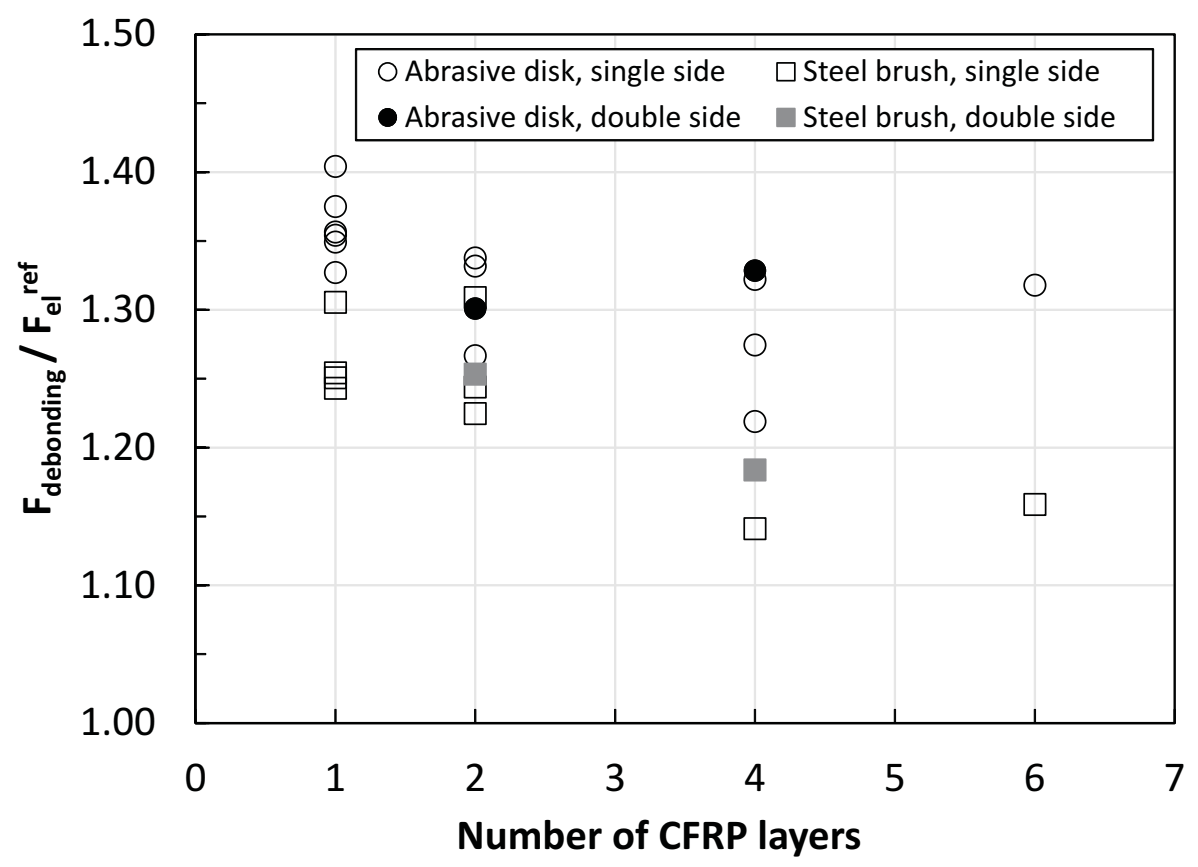

FIG. 12. Ratio between the debonding and elastic force of reinforced steel plates vs Number of CFRP layers. 


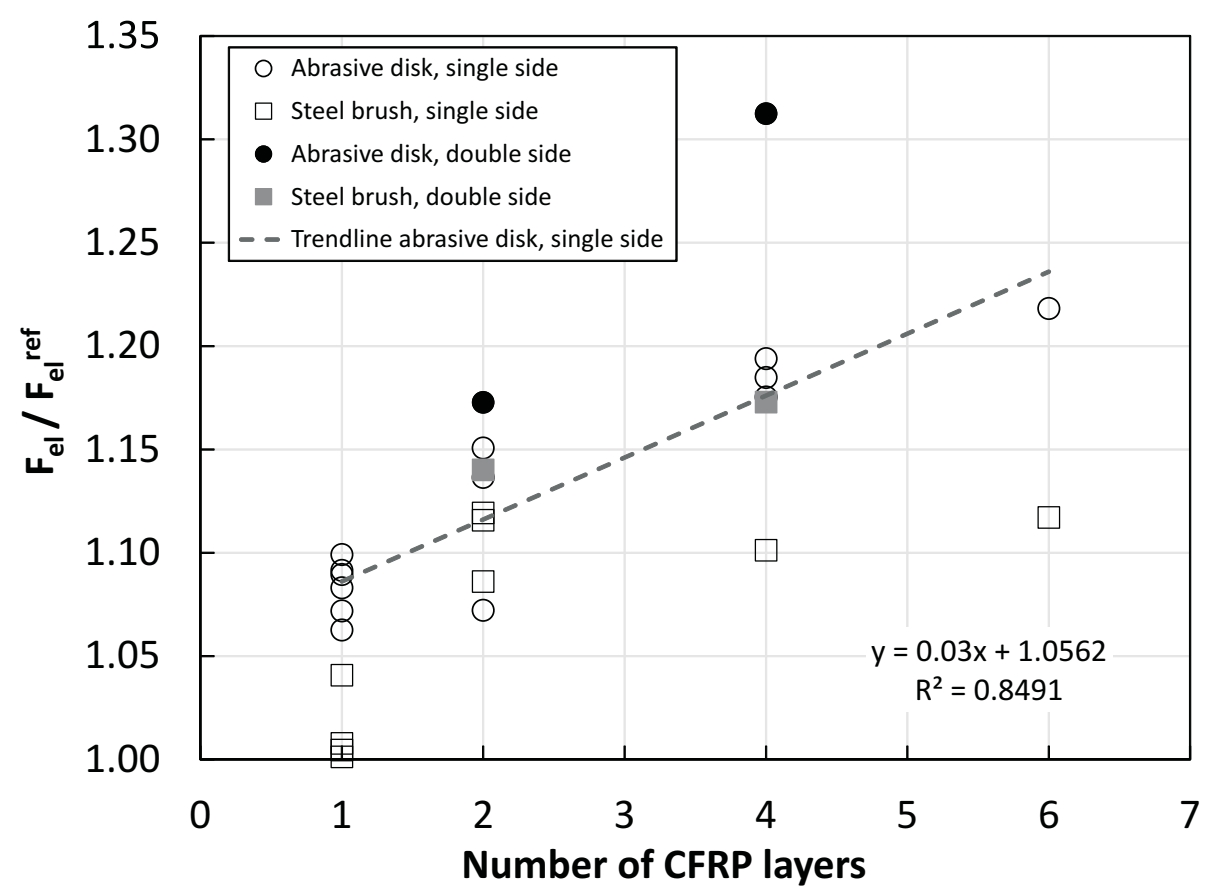

FIG. 13. Ratio between the elastic force of steel plates with and without reinforcement vs number of CFRP layers. 